Document downloaded from:

http://hdl.handle.net/10251/34798

This paper must be cited as:

Cortes, JM.; Pellicer Armiñana, E.; Catalá Alís, J. (2012). Integration of occupational risk prevention courses in engineering degrees: Delphi study. Journal of Professional Issues in Engineering Education and Practice. 138(1):31-36. doi:10.1061/(ASCE)El.19435541.0000076

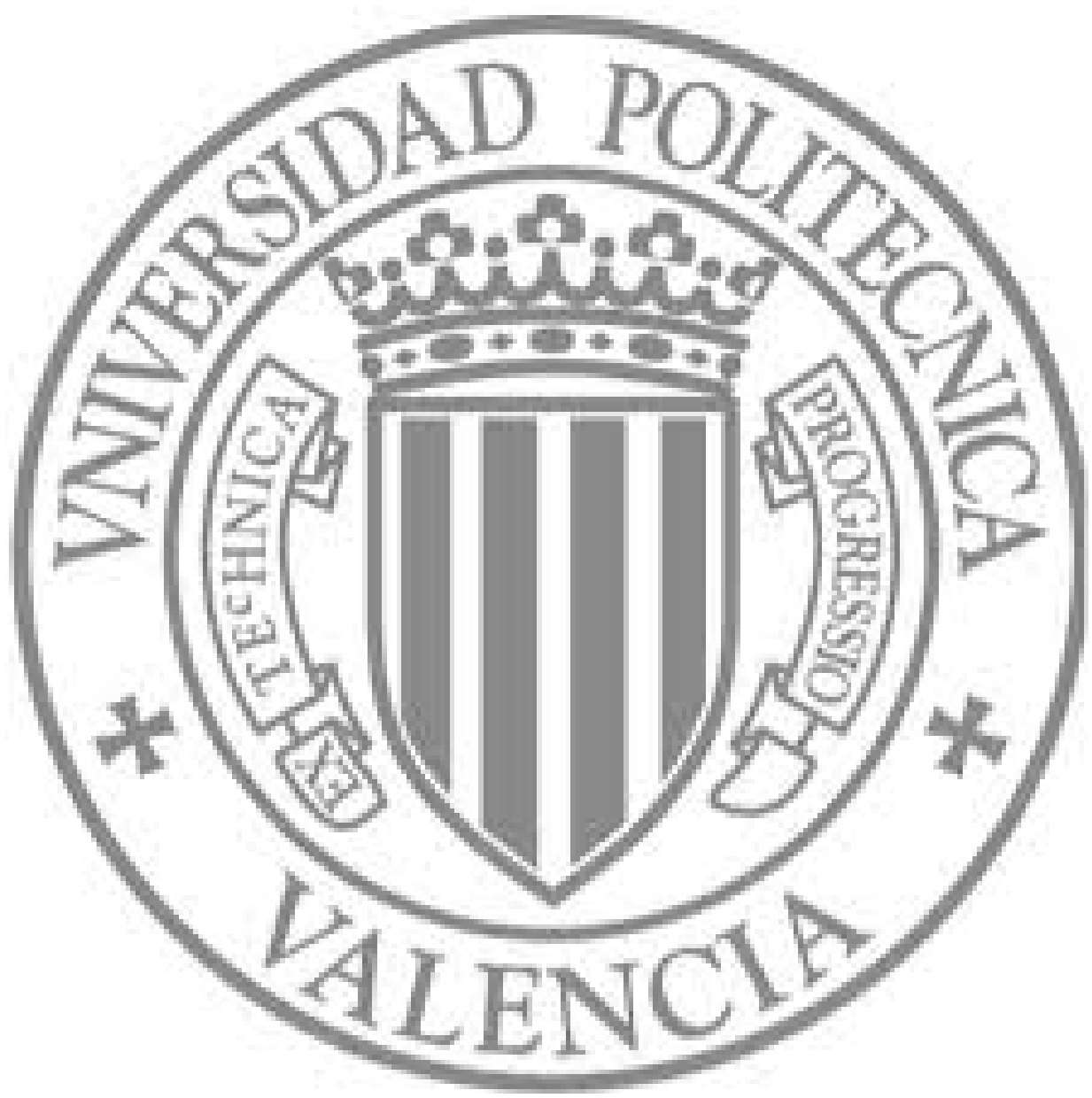

The final publication is available at

http://dx.doi.org/10.1061/(ASCE)El.1943-5541.0000076

Copyright American Society of Civil Engineers 


\title{
INTEGRATION OF OCCUPATIONAL RISK PREVENTION COURSES IN ENGINEERING DEGREES: A DELPHI STUDY
}

\author{
By José M. Cortes ${ }^{1}$, Eugenio Pellicer ${ }^{2}$ (M.ASCE), Joaquín Catala ${ }^{3}$
}

\begin{abstract}
Engineering syllabuses often lack courses covering occupational risk prevention. In Spain, professional competences are awarded along with the completion of a university degree. This means that new graduates are certified in areas where they have received little or no training, such as occupational risk prevention. However, the academic reforms established by the Bologna Process, which strives to homogenize university degrees throughout Europe, compels European universities to design new syllabuses. The main goal of this paper is to define a framework for including occupational risk prevention education in the new engineering syllabuses. This exploratory research applied the Delphi methodology to a panel of 59 experts using questionnaires assessed with a four-point Likert scale through two rounds. A Web site supported all the information flow. According to the experts who participated in this study, education and training in occupational risk prevention is essential for improving the safety culture within a company or workplace. They concurred that this subject should be a separate mandatory course in all engineering degree programs. The participants recommended that an optional course should be considered only if a mandatory course is not approved. It was also deemed desirable to integrate occupational risk prevention as a cross-field subject in other technological courses, even if the syllabus already includes some related courses.
\end{abstract}

\section{KEYWORDS}

Delphi - Education - Engineering - Prevention - Occupational - Risk

\section{INTRODUCTION}

The occupational accident rate is currently one of the main concerns of Western societies and governments. This is especially true in Spain, where the occupational fatality rate is far higher than the European average (Pellicer et al. 2005, Rubio et al. 2005). The number of occupational accidents has continued to grow steadily, from 677,138 (1997) to 924,981 (2007), despite the fact that it seems to have stabilized around 900,000 accidents during the present decade (INE 2009). While workers' health is invaluable, these accidents also have a huge economic cost (Leopold and Leonard 1987, Levitt and Samelson 1993, Everett and Frank 1996, Waehrer et al. 2007).

According to Spanish regulations and laws, university graduates that hold an engineering degree are allowed full professional practice in their field without any further accreditation or training (EU 2005, Rubio et al. 2005, Cortés et al. 2009b). This scenario differs significantly from countries that follow a system similar to that of the US or UK, where professional qualifications are awarded by professional bodies in line with their charters through experience, examination, or both (EU 2005). Most Spanish engineers have professional competences regarding safety and health in their industries simply because they have graduated with a degree in engineering (Cortés et al. 2009b).

Due to the fact that these professional competences are acquired as a direct consequence of graduation, university syllabuses should offer instruction in occupational risk prevention. However, this is not the current scenario (Cortés et al. 2009a, 2009b). Lack of specific education and training in occupational safety and health for engineering professionals has been discussed in the work of many authors since

\footnotetext{
${ }^{1}$ Associate Professor, Department of Mechanical and Materials Engineering, Universidad de Sevilla, Camino de los Descubrimientos sn, Isla Cartuja, 41092 Sevilla, Spain

${ }^{2}$ Associate Professor, School of Civil Engineering, Universidad Politécnica de Valencia, Camino de Vera sn, 46022 Valencia, Spain. Corresponding author: Phone +34963879562; Fax: +34963877569; E-mail: pellicer@cst.upv.es

${ }^{3}$ Professor, School of Civil Engineering, Universidad Politécnica de Valencia, Camino de Vera sn, 46022 Valencia, Spain
} 
the eighties (Hale et al. 1984, Talty 1986, Levitzky 1988, Kavianian et al. 1993, Bryan 1999, Hill and Nelson 2005, Rodrigues and Teixeira 2002, Ferjencik 2007, Petersen et al. 2008, Pellicer and Molenaar 2009).

Several authors and professional associations throughout the last two decades maintained that this lack of engineering education should be solved at the university level. Once the specific shortcomings in the preparation of engineers have been determined, measures can be taken immediately by the faculty in order to improve the current situation. Up until now_four approaches have been considered to enhance engineering education regarding occupational risk prevention. They imply the introduction of: (1) a new degree (Hale et al. 1984, Alhemood 2004, Vincent 2005); (2) a new course in an existing degree (Talty 1986, Moccaldi et al. 2005, Ferjencik 2007); (3) relevant topics or a cross-field subject in several courses of the current syllabus (Lemkowitz 1992, Hill and Nelson 2005, Petersen et al. 2008); or (4) relevant topics in one specific course of the current syllabus (Kauffman 1987, Levitzky 1988, Phillis and Wheway 1991).

An in-depth analysis of the Spanish scenario was carried out by Cortés (2009) and Cortés et al. (2009a,b). These authors analyzed governmental regulations regarding 69 bachelor degrees that had some relation to labor risk prevention, and their consequent implementation in 464 university syllabuses. Throughout their extensive research, the authors demonstrated that courses related to occupational risk prevention were rarely included in Spanish engineering syllabuses and very few specific courses on safety and health were offered, and when offered they were usually elective.

The Bologna Process establishes a new academic scenario that requires participating European governments to reform their university systems (Reinalda and Kulesza 2005). This means that every university degree in the European Union must comply with three basic requirements (Bologna Secretariat 2010): (a) degrees are organized in a three-cycle structure (bachelor-master-doctorate); (b) quality is assured in accordance with defined standards and guidelines; and (c) fair recognition of foreign degrees in accordance with the UNESCO Recognition Convention. The majority of Spanish universities are currently developing new syllabuses in Engineering for Bachelor's and Master's degrees based on the Bologna Process and further regulations dictated by the Spanish Ministry of Education. Generally the graduate level is a 4-year degree, and the post-graduate degree is 2 years. The design is very similar to the current U.S. system.

Regulations issued by the Spanish Government regarding these new degrees state specifically that students must acquire the competences needed for professional practice. However, in most of these degrees, no explicit references are made to competences in occupational risk prevention. The result is that universities do not have to consider safety and health as a mandatory subject. The Bologna Process represents an opportunity to improve engineering syllabuses regarding occupational risk prevention.

Having stated the problem to be addressed, the main goal of this research can be outlined. We aim to define a minimum framework for the implementation of occupational risk prevention issues in the new engineering syllabuses that are currently being designed in Spain to comply with the Bologna Process. This paper is structured as follows. First, the exploratory methodology, which is based on the Delphi method, is stated. Several issues regarding this method are briefly explained: theoretical background, panel composition, computer software used as a survey tool, survey process, content of questionnaires, and survey assessment. Second, the results are presented and the implications are discussed. Finally, concluding remarks are given. 


\section{METHODOLOGY}

\section{Delphi Method}

In the field of qualitative research, the Delphi method seeks to obtain a reliable group opinion from information provided by a panel of experts who are asked for their point of views individually regarding a number of issues in a systematic and interactive manner (Linstone and Turoff 1975). Data is obtained using a series of questionnaires. Through these questionnaires experts anonymously make their estimates in successive rounds in order to achieve maximum consensus while maintaining maximum participant autonomy. The questionnaires can be distributed in person, by e-mail, or via the Web. The study leader or facilitator picks the experts following a pre-defined pattern, develops questionnaires, analyzes the responses, and extracts conclusions. The method follows an iterative process, carried out by anonymous experts and led by the facilitator, who presents feedback and analyzes results, using statistics if necessary. A detailed comparison of conventional survey research and the Delphi method can be found in Okoli and Pawlowski (2004).

The application of the Delphi technique involves the application of the steps specified in Fig. 1. To perform a rigorous implementation of the Delphi method, the authors of this paper follow the specific guidelines proposed by Hallowell and Gambatese (2010) regarding expertise requirements, number of panel members, feedback process, number of rounds, and measurement of consensus. They are explained in the following sub-sections.

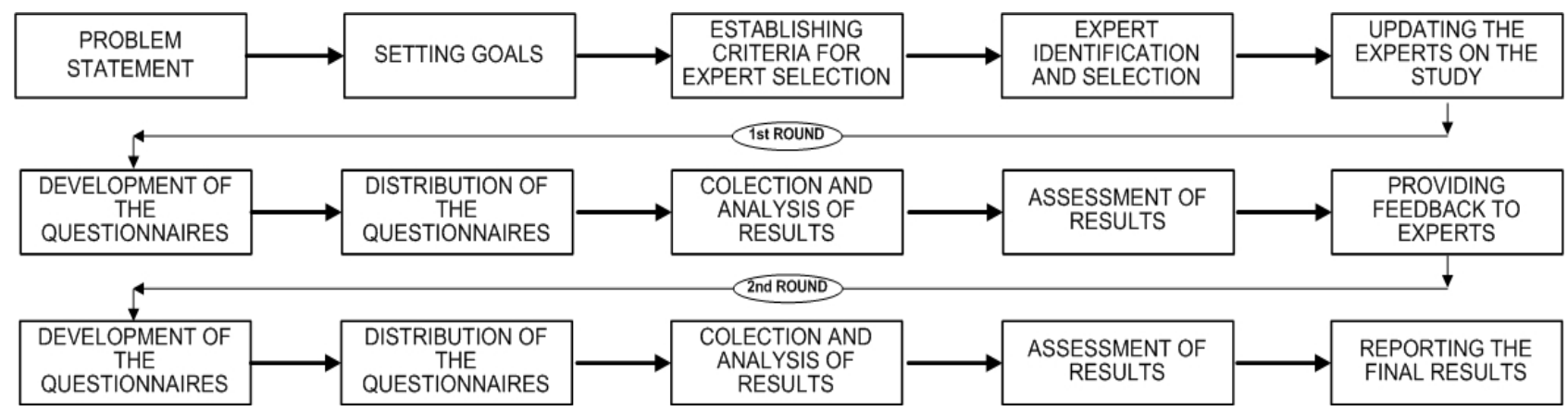

Figure 1. Procedure of implementation of the Delphi method (adapted from Hallowell and Gambatese, 2010).

\section{Panel Composition}

A minimum of 10 experts is generally acceptable (Okoli and Pawlowski 2004). For this investigation it was considered appropriate to have a total of 60 experts on the panel. They were originally selected according to specific profiles; however, a mandatory requirement for all of them was to have a minimum experience of ten years in their respective fields. The profiles were defined as followed:

A. University professors who teach specific occupational risk prevention courses: 12 professors from 11 different universities.

B. University professors who teach other technological courses: 10 professors from 5 different universities; they are from different departments than the previous profile.

C. Professional engineers or architects with proven experience in occupational risk prevention: a total of 37 professionals coming from public agencies (8), mutual insurance societies for work-related accidents and illnesses (6), specialized companies in occupational risk prevention and audit firms (8), other work posts related to safety and health in engineering companies (6), and finally, work posts not directly related to safety and health issues (9).

One of the experts renounced participation, resulting in a final panel figure of 59. Table 1 shows the exact distribution by profile and academic degree. The proportion of experts by profession follows, roughly, the current distribution of alumni in Spain (INE 2010), with industrial engineering (including mechanical and chemical, among others) being the majority of the market, followed by construction 
industry professionals. Medicine was included to show a view of the problem from a health perspective.

\begin{tabular}{|c|c|c|c|c|c|}
\hline \multirow{2}{*}{ ACADEMIC DEGREE } & \multicolumn{3}{|c|}{ PROFILE } & \multirow{2}{*}{ Total } & \multirow{2}{*}{$\%$} \\
\hline & A & $\mathbf{B}$ & $\mathbf{C}$ & & \\
\hline Architecture and Quantity Surveying & 3 & 1 & 3 & 7 & $11.9 \%$ \\
\hline Aeronautical Engineering & & & 1 & 1 & $1.7 \%$ \\
\hline Agronomic and Forest Engineering & 1 & & 5 & 6 & $10.2 \%$ \\
\hline Civil Engineering & & 2 & & 2 & $3.4 \%$ \\
\hline Industrial Engineering & 3 & 7 & 22 & 32 & $54.1 \%$ \\
\hline Mining Engineering & 1 & & 2 & 3 & $5.1 \%$ \\
\hline Electrical Engineering & & & 1 & 1 & $1.7 \%$ \\
\hline Naval Engineering & & & 3 & 3 & $5.1 \%$ \\
\hline Medicine & 4 & & & 4 & $6.8 \%$ \\
\hline Total & 12 & 10 & 37 & 59 & $100.0 \%$ \\
\hline $\begin{array}{l}\text { A. University professors who teach specifi } \\
\text { B. University professors who teach other te } \\
\text { C. Professional engineers or architects prad }\end{array}$ & $\begin{array}{l}\text { ional } \\
\text { cal ce } \\
\text { ccup }\end{array}$ & $\begin{array}{l}\text { K pre } \\
\text { ses } \\
\text { onal }\end{array}$ & & & \\
\hline
\end{tabular}

Table 1. Distribution of experts per profile and academic degree

\section{Survey Tool}

The research described in this paper takes advantage of the use of information technologies, using an online application to support the information flow between the facilitator and the experts. This approach accelerated interaction with the panel members, making participation easier.

A Web page was designed to carry out the prospective study, allowing the experts to access the necessary information which included the application of the Delphi technique, new university requirements regarding the Bologna Process, and associated regulations for occupational risk prevention. The Web site designed was located at www.seguridadintegral.eu/prospectivaprl. The experts could access the site using the appropriate username and password supplied by the facilitator.

A description of the method and the objectives pursued by the study was first performed via mail; later, once the experts decided to participate, the facilitator answered specific questions and offered further details, if necessary, through telephone conversations and face-to-face meetings. The opinions given by the experts were analyzed and processed and then taken into account in the following round. This achieved the desired exchange of views while maintaining the anonymity of participants. The information generated (explanation of the method, questionnaires, and results of previous circulations) was integrated into one place of reference making access faster and more effective for participants.

\section{Survey Process}

In order to achieve the best results in the shortest time, the authors sought to use the least number of rounds without losing accuracy or rigor. Two rounds were planned, with the possibility of a third if necessary depending on the degree of consensus achieved after the second round. The feedback process required informing the experts about the group's views before proceeding to a new round. Meanwhile, results from the previous round were released through the Web as feedback for the members of the panel. The experts received the new questionnaire and were asked again about the issues raised. According to Best (1974), those experts who were given feedback greatly improved the accuracy of later rounds. 


\section{Questionnaires' Content}

Questionnaires requested information regarding two main issues:

a) Do engineers need specific undergraduate education in occupational risk prevention as a consequence of their professional activity?

b) How can occupational risk prevention be integrated into undergraduate engineering degree syllabuses?

\section{Survey Instrument}

A Likert scale was used to quantify the responses. This scale is composed of items or statements which the respondent is asked to assess according to some type of subjective or objective criteria. Therefore, his/her level of agreement or disagreement is quantified. A four-point scale was used, with four possible choices: strongly agree, agree, disagree, or strongly disagree. This is a forced choice method (Cohen et al. 2000) since the middle point of "neither agree nor disagree" is not offered. A score was given to each of the alternative choices, from 0 (strongly disagree) to 3 (strongly agree); this way, responses to these questions could be analyzed statistically by calculating their mean.

\section{RESULTS}

The final results of the Delphi method are presented in Table 2; these values include not only the overall mean per question, but also the specific mean for each one of the three profiles defined in Table 1 . Once the $1^{\text {st }}$ round of questionnaires was answered by the panel members, two questions $\left(1^{\text {st }}\right.$ and $4^{\text {th }}$ ) were slightly changed for the $2^{\text {nd }}$ round because it was detected that they generated confusion. Also, a complete report on the results was handed out to each of the experts. During the $2^{\text {nd }}$ round the experts confirmed or varied very little from their original opinions. In the ensuing discussion the reasoning of some of the experts was included, generally those who provided comments that added value to the research. According to Rowe and Wright (1999), this procedure leads to more accurate results.

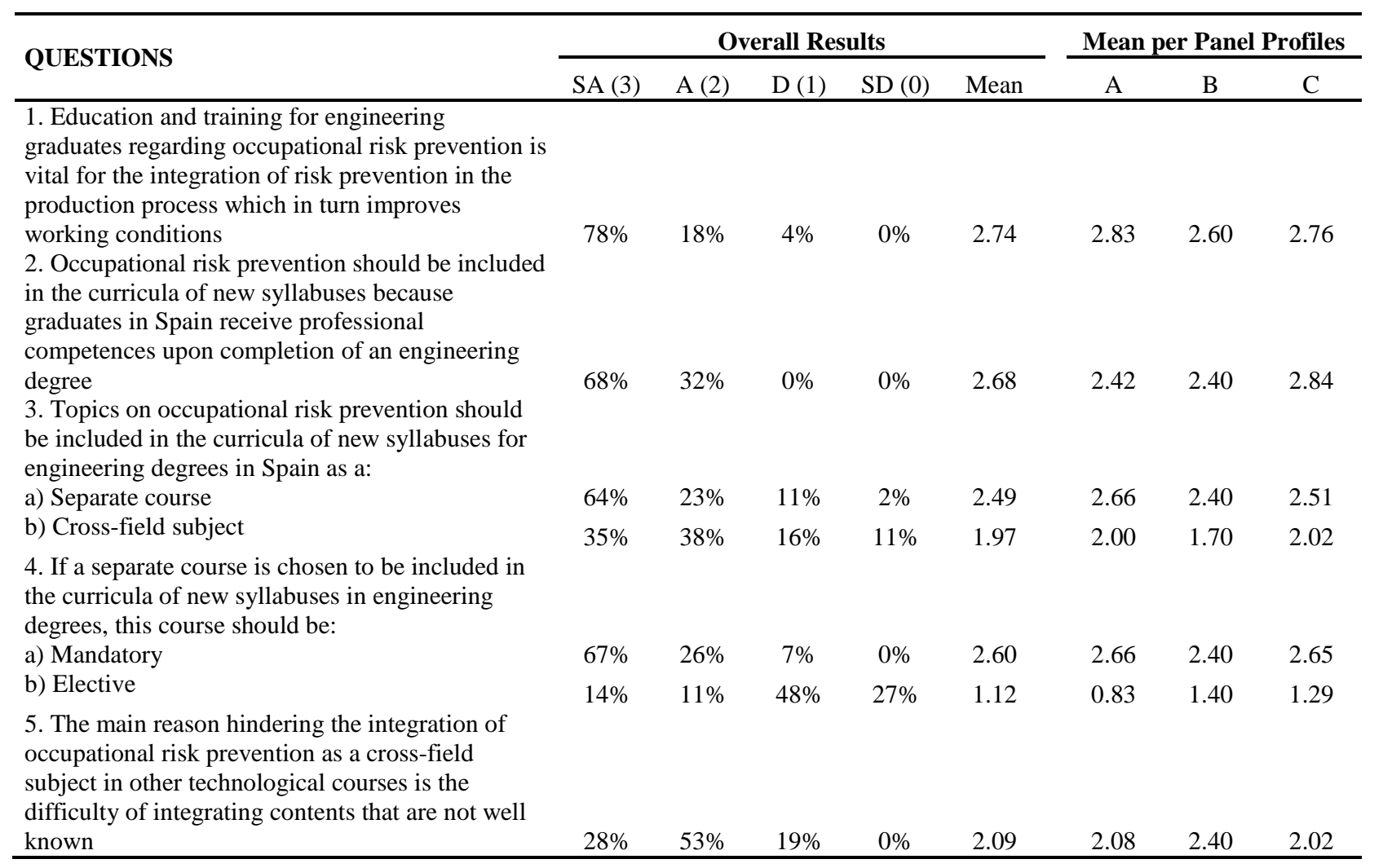




\begin{tabular}{|c|c|c|c|c|c|c|c|c|}
\hline \multirow{2}{*}{ QUESTIONS } & \multicolumn{5}{|c|}{ Overall Results } & \multicolumn{3}{|c|}{ Mean per Panel Profiles } \\
\hline & SA (3) & $A(2)$ & $\mathrm{D}(1)$ & $\mathrm{SD}(0)$ & Mean & A & B & C \\
\hline $\begin{array}{l}\text { 6. If you are a professor who teaches a course on } \\
\text { engineering technology: are you willing to } \\
\text { integrate occupational risk prevention in the course } \\
\text { you teach? }\end{array}$ & $50 \%$ & $31 \%$ & $19 \%$ & $0 \%$ & 2.31 & -- & 2.31 & -- \\
\hline 7. What name would be best for the new course? & & & & & & & & \\
\hline a) Safety and Health & $12 \%$ & $25 \%$ & $40 \%$ & $23 \%$ & 1.26 & 1.08 & 1.10 & 1.37 \\
\hline b) Occupational Risk Prevention & $52 \%$ & $42 \%$ & $4 \%$ & $2 \%$ & 2.44 & 2.42 & 2.30 & 2.51 \\
\hline $\begin{array}{l}\text { c) Industrial Safety } \\
\text { 8. Which of the following issues should be } \\
\text { considered as part of the course? }\end{array}$ & $7 \%$ & $18 \%$ & $45 \%$ & $30 \%$ & 1.02 & 0.56 & 1.20 & 1.11 \\
\hline a) Basic Concepts and Terminology & $51 \%$ & $40 \%$ & $5 \%$ & $4 \%$ & 2.38 & 2.58 & 2.30 & 2.35 \\
\hline b) Laws and Regulations & $58 \%$ & $38 \%$ & $4 \%$ & $0 \%$ & 2.54 & 2.66 & 2.20 & 2.62 \\
\hline c) Industrial Safety & $38 \%$ & $58 \%$ & $2 \%$ & $4 \%$ & 2.32 & 1.91 & 2.10 & 2.40 \\
\hline d) Risk Assessment & $64 \%$ & $32 \%$ & $4 \%$ & $0 \%$ & 2.60 & 2.58 & 2.40 & 2.57 \\
\hline $\begin{array}{l}\text { e) Health and Safety Plan } \\
\text { f) Integrating Occupational Risk Prevention in the }\end{array}$ & $60 \%$ & $38 \%$ & $2 \%$ & $0 \%$ & 2.58 & 2.41 & 2.60 & 2.65 \\
\hline Production Process & $72 \%$ & $28 \%$ & $0 \%$ & $0 \%$ & 2.72 & 2.58 & 2.60 & 2.65 \\
\hline g) Occupational Risk Prevention at the Work Site & $51 \%$ & $40 \%$ & $9 \%$ & $0 \%$ & 2.42 & 2.33 & 2.30 & 2.48 \\
\hline $\begin{array}{l}\text { SA = Strongly Agree } \\
\text { A= Agree } \\
\text { D = Disagree } \\
\text { SD = Strongly Disagree } \\
\end{array}$ & & & & & & & & \\
\hline
\end{tabular}

Table 2. Questions and answers to the survey $\left(2^{\text {nd }}\right.$ round $)$

\section{DISCUSSION}

The results of the survey (listed in Table 2) demonstrate, on the one hand, the high degree of consensus reached by the experts in relation to each of the questions, and on the other hand, contributions and arguments presented in support of their opinions. The results by member profile (see Table 2) are generally quite similar; nevertheless, some discrepancies appear and they will be highlighted further in this section.

An agreement was reached that this subject should be included in all engineering degree syllabuses because occupational hazards are present in all productive sectors and all of them require integrating prevention in productive and managerial processes. They believed that: (a) there is a relationship between the usual roles played by engineers during the phases of feasibility, design, construction and operation, and their impact on improving working conditions; and (b) engineering graduates not only influence the integration of prevention in the production process, but also promote a safety culture within the company. However, some experts pointed out that "degrees such as electrical engineering or computer science do not require instruction in occupational risk prevention”.

The panel was unanimous in considering that the Government of Spain should include occupational risk prevention in the curricula of the new syllabuses for engineering degrees. Since professional competences are acquired when university degrees are awarded chartered professionals would then be able to perform occupational risk prevention activities in their respective fields, related to design, construction, and fabrication or installation of facilities or equipment. The group of professional engineers (profile C) was the most supportive of this regulatory approach, perhaps because they experience the day-to-day harsh professional environment. Some of the experts considered occupational risk prevention "strategic in engineering". Others considered that "it is irrational to provide education and training only in technological tasks", regardless of any others necessary to avoid damage to persons or the environment. 
The next issue assessed was whether or not occupational risk prevention should be included in the curricula of new syllabuses in engineering degrees as a separate course or as a cross-field subject. The general opinion of the experts indicated that the best option was an independent course. Most of the panelists thought that this was the most desirable way to integrate occupational risk prevention in society: "separating their teaching from other courses".

The cross-field course must be understood as complementary to the specific one; many experts suggested that the topic has to be "included in other technological courses as a cross-field subject also". Other experts argued that "this course could be integrated with quality, environmental and sustainability issues", because the goal is to prevent harm to both people and the environment in a broad sense, and to the product life cycle in a more specific sense. Some of the panelists also recommended the inclusion of occupational risk prevention in technological areas such as construction processes, equipment and machinery, or industrialization, as well as in other broader matters: design engineering, human resources management, or worksite organization. However, professors teaching these courses (profile B) were not as convinced as the other groups, perhaps because they are the ones that are more familiar with the problem and also the ones that will have to endure the issue.

Regardless of whether or not this course should be mandatory or elective, most of the respondents agreed that the prevention of occupational hazards should be included as a compulsory subject in the new engineering curricula. In line with the majority view expressed by the experts regarding this question, most of them disagreed with treating it as an optional subject; professors teaching occupational risk prevention (profile A) were clearly against this option, which might have been because they were an interested party. Some panelists voiced this option only as "the lesser of two evils”.

Most of the experts agreed that the lack of knowledge about the subject hinders the integration of occupational risk prevention in technological courses taught by the engineering faculty. This is especially true for professors teaching technological courses (profile B), who are possibly more familiar with the situation. Besides the lack of knowledge on this matter, the experts pointed out the "failure to grant priority to this aspect", "students' academic overload", and "excessive contents of the courses" as other reasons for the failure to integrate occupational risk prevention issues in other technological courses. However, some panelists insisted that this integration must be pursued not only in the contents of their courses, but also "lecturing with a safety culture attitude because professors are educating future engineers that will manage human lives”.

Moreover, more than $80 \%$ of the professors teaching courses on engineering technology showed their willingness to integrate occupational risk prevention into their courses. Some of them already teach courses that integrate occupational risk prevention whereas others are willing to do so if the necessary information is provided.

Regarding the name of the course, almost all respondents agreed that the designation of "occupational risk prevention" was the most appropriate to describe this subject. According to the experts this designation has a wider meaning than the two other terms considered and is more in line with the existing legislation. The participants associated "occupational safety and health" as "a concept more identified with the issues related to techniques, equipment and materials used in the production processes", instead of a concept that covers analysis and control of hazards that can appear at the work site. The term "industrial safety" was considered "a very restrictive term focused on manufacturing only”, being disliked by most of the respondents.

Most experts agreed that the contents proposed in the last question of the survey were generally suitable for the course. Some of them, however, argued that industrial safety is not essential, mainly in those fields related to the construction industry. They suggested the inclusion of other subjects such as 
duties, responsibilities, information, education, public consultation and management in the field of occupational risk prevention. Some experts proposed again that the general topic of sustainability in the built environment could also be considered as introductory.

\section{CONCLUSIONS}

As a result of the qualitative research, the most relevant conclusions come from the views expressed by panel members participating in the investigation. Education and training in occupational risk prevention has a direct impact on improving working conditions; it is considered essential for the necessary generation of a safety culture in a company. This subject should be mandatory in every engineering degree, not only because of the professional competences that engineers acquire as a consequence of their university graduation in Spain, but also because of the effects that their actions may have on the health and safety of persons involved during the production process, and the later operation of the product or infrastructure.

Occupational risk prevention should be taken into account in the guidelines issued by the Spanish government for the development of new university syllabuses. These degrees should lead to the acquisition of the skills necessary for exercising different chartered engineering professions. Thus, these competences need to be included in their syllabuses.

Occupational risk prevention should be a separate mandatory course. A compulsory course would only be included if a mandatory course was not approved. However, it would also be desirable to integrate occupational risk prevention as a cross-field subject in other technological courses, even if the syllabus already includes some related courses. The lack of knowledge of some professors related to occupational risk prevention might hinder this process. These professors could receive minimal training on the subject, including basic occupational risk prevention concepts and terminology and the most notable aspects of legislation, risk assessment, prevention procedures at the work site, or the integration of occupational risk prevention in the design or production process.

Finally, the authors believe that the main questions of this research have been proven for the Spanish scenario and that the conclusions are applicable to other Western nations as well. Nevertheless, this study can be replicated in other countries in order to test the suitability of the analysis and generalize results. Future work should address important aspects like associated costs, more detailed contents, and timing, among others.

\section{ACKNOWLEDGMENTS}

The authors wish to thank Lia Wallon for revising the text, and also acknowledge the valuable suggestions of two anonymous reviewers.

\section{REFERENCES}

Alhemood, A. (2004) "Development of safety engineering curricula in the Gulf Cooperative countries to meet local manufacturing needs”. Human Factors and Ergonomics in Manufacturing, 14, 321-326.

Bologna Secretariat (2010) Towards the European Higher Education Area: Bologna process. Retrieved on October $25^{\text {th }}$ from: http://www.ond.vlaanderen.be/hogeronderwijs/bologna/about/.

Bryan, L.A. (1999) "Educating engineers on safety”. Journal of Management in Engineering, 15(2), 30-33.

Cohen, L., Manion, L. and Morrison, K. (2000) Research methods in education (5 ${ }^{\text {th }}$ edn). Routledge, London.

Cooper, M. D. (2000) “Towards a model of safety culture”. Safety Science, 36(2), 111-136. 
Cortés, J.M. (2009) La prevención de riesgos laborales en las enseñanzas universitarias españolas y su integración en los estudios de ingeniería. Ph.D. Thesis. Universidad Politécnica de Valencia, Valencia (in Spanish).

Cortés, J.M., Catalá, J. and Pellicer, E. (2009a) “El técnico superior de prevención de riesgos laborales como nueva profesión regulada. Propuestas de titulación oficial y requisitos que serían necesarios para la verificación”. XVII Congreso Universitario de Innovación Educativa en las Enseñanzas Técnicas, 15-18 September, Valencia (in Spanish).

Cortés, J.M., Catalá, J. and Pellicer, E. (2009b) “La prevención de riesgos laborales en las enseñanzas de ingeniería: competencias y requisitos para la verificación de los títulos que habilitan para el desempeño de profesiones reguladas”. XVII Congreso Universitario de Innovación Educativa en las Enseñanzas Técnicas, 15-18 September, Valencia (in Spanish).

Elangovan, R.K., Mohammed, K.P. and Mohan, S. (2005) "Effectiveness of the designed safety education programme modules by their implementation in selected industries". Journal of Loss Prevention in the Process Industries, 18, 553-557.

EU (2005) Directive 2005/36/EC, adopted on 7 September 2005, consolidates and modernises the rules currently regulating the recognition of professional qualifications. European Commission, Brussels.

Everett, J.G. and Frank, P.B. (1996) "Cost of accidents and injuries to the construction industry”. Journal of Construction Engineering and Management, 122(2), 158-164.

Ferjencik, M. (2007) “Best starting point to comprehensive process safety education”. Process Safety Progress, 26(3), 195-202.

Findley, M., Smith, S.M., Kress, T., Petty, G. and Enoch, K. (2004) "Safety program elements in construction”. Professional Safety, February, 14-21.

Hale, A.R. (1984) “Is safety training worthwhile?” Journal of Occupational Accidents, 6, 17-33.

Hallowell, M.R. and Gambatese, J.A. (2010) "Qualitative research: application of the Delphi method to CEM research”. Journal of Construction Engineering and Management, 136(1), 99-107.

Hill, R.H. and Nelson, D.A. (2005) “Strengthening safety education of chemistry undergraduates". Chemical Health \& Safety, November/December, 19-23.

INE (2009) Instituto Nacional de Estadística. Mercado laboral. Accidentes de trabajo y enfermedades profesionales. Serie 1997-2007. Retrieved on December $14^{\text {th }}$ from:

http://www.ine.es/jaxi/menu.do?type=pcaxis\&path=/t22/a063/a1998/\&file=pcaxis (in Spanish).

INE (2010) Instituto Nacional de Estadística. Estadística de Enseñanza Universitaria. Retrieved on October $26^{\text {th }}$ from:

http://www.ine.es/jaxi/menu.do?type=pcaxis\&path=\%2Ft13\%2Fp405\&file=inebase \&L=0 (in Spanish).

Kauffman, D. (1987) “Health, safety and loss control topics in the senior design courses”. Plant/Operation Progress, 6(2), 73-76.

Kavianian, H.R., Meshkati, N., Wentz, C.A. and Rao, J.K. (1993) "Should engineering schools address occupational and environmental safety and health issues?”. Professional Safety, 38(6), 48-49.

Lemkowitz, S.M. (1992) “A unique program for integrating health, safety, environment and social aspects into undergraduate chemical engineering education”. Plant/Operation Progress, 11(3), 140-150.

Leopold, E. and Leonard, S. (1987) "Cost of construction accidents to employers". Journal of Occupational Accidents, 8, 273-294.

Levitt, R. and Samelson, N.M. (1993) Construction safety management ( $2^{\text {nd }}$ edn). Wiley, New York.

Levitzky, J.J. (1988) "Safety, health, and loss prevention in the undergraduate chemical engineering curriculum”. Plant/Operations Progress, 7(3), 190-194.

Linstone, H.A. and Turoff, M. (1975) The Delphi method: techniques and applications. AddisonWesley, London.

Moccaldi, A., Trevisi, R. and Orlando, C. (2005) "ISPESL radon programme: a challenge in the academic programme of a safety and security engineering course”. Safety and Security Engineering, 82, 143-150. 
Okoli, C. and Pawlowski, S.D. (2004) "The Delphi method as a research tool: an example, design considerations and applications”. Information \& Management, 42, 15-29.

Pellicer, E. and Molenaar, K.R. (2009) "Discussion of 'Developing a model of construction safety culture””. Journal of Management in Engineering, 25(1), 44-47.

Pellicer, E., Serón, J., Catalá, J. and Jordá, L. (2003). "Proposal of a new academic frame for the civil engineering education in construction safety and health". Proceedings of the International Conference on Engineering Education, Valencia, 264 (abstract).

Petersen, A.K., Reynolds, J.H. and Ng, L.W.T. (2008) "The attitude of civil engineering students towards health and safety risk management: a case study”. European Journal of Engineering Education, 33(5-6), 499-510.

Phillis, T.W. and Wheway, R.T. (1991) "Introducing occupational health and safety issues to undergraduate students: the Wollonong experience”. International Mechanical Engineering Congress, 8-12 July, Sidney.

Reinalda, B. and Kulesza, E. (2005) The Bologna process - harmonizing Europe's higher education. Barbara Budrich Publishers, Farmington Hills (MI).

Rodrigues, M.F. and Teixeira, J.C. (2002) "Health and safety in Portuguese civil engineering curricula”. XXX IAHS World Congress on Housing, Housing Construction: an Interdisciplinary Task, Coimbra (Portugal), 67-71.

Rowe, G. and Wright, G. (1999) “The Delphi technique as a forecasting tool: issue and analysis”. International Journal of Forecasting, 15, 353-375.

Rubio, M.C., Menéndez, A., Rubio, J.C. and Martínez, G. (2005) “Obligations and responsibilities of civil engineers for the prevention of labour risks. References to European regulations”. Journal of Professional Issues in Engineering Education and Practice, 131(1), 70-75.

Talty, J.T. (1986) "Integrating safety and health issues into engineering school curricula”. Chemical Engineering Progress, October, 13-16.

Vincent, J.H. (2005) “Graduate education in occupational hygiene: a rational framework”. The Annals of Occupational Hygiene, 49(8), 649-659.

Waehrer, G.M., Dong, X.S., Miller, T., Haile, E. and Men, Y. (2007) "Cost of occupational injuries in construction in the United States”. Accident Analysis and Prevention, 39, 1258-1266. 